\title{
Does environmental performance leverage the impact of environmental strategy on financial performance? A focus on third-party logistic providers
}

\author{
Quang-Huy Ngo ${ }^{a^{*}}$
}

\begin{tabular}{l}
${ }^{a}$ FPT University, Vietnam \\
\hline A B S T R A C T \\
\hline Article history: \\
Received July 18, 2021 \\
Received in revised format \\
September 24, 2021 \\
Accepted October 302021 \\
Available online \\
October 30 2021 \\
\hline Keywords: \\
Environmental performance \\
Environmental strategy \\
Natural resource-based view \\
Third-party logistics \\
Vietnam
\end{tabular}

\section{Introduction}

There is a concern that the conventional operation of enterprise may have a negative impact on the natural environment. In this regard, enterprises nowadays not only focus on the improvement of financial performance (FP) but also environmental performance (EP). To gain the improvement in such regard, environmental strategy (ES) should be taken into account. Prior studies reveal that this strategy has a positive impact on FP (Aragón-Correa, Hurtado-Torres, Sharma, \& García-Morales, 2008) and EP (see Kraus, Rehman, \& García, 2020; Latan, Jabbour, de Sousa Jabbour, Wamba, \& Shahbaz, 2018; Solovida \& Latan, 2017). When examining the link between ES and FP, a meta-analytical review (see Albertini, 2013) suggests that the positive effects of this link are not always found in empirical studies. Instead, this relationship may be positive, negative and even neutral. Recently, scholars raise a concern that the link between ES and FP is influenced by mediators (Li, Jayaraman, Paulraj, \& Shang, 2016). Consistently, some studies reveal that EP is the mediator on the link between environmental management practices and FP (Aslam, Elmagrhi, Rehman, \& Ntim, 2021; Feng, Yu, Wang, Wong, Xu, \& Xiao, 2018). These findings can be drawn upon the natural resource-based view (NBRV) (Hart, 1995), which indicates that enterprises can sustain their competitive advantages when they align their operations in line with the protection of the natural environment . In this regard, it may expect that ES may permit EP, which in turn results in FP. However, this study addresses several gaps in the literature. First, although pursuit of ES encourages enterprises to gain both FP and EP, there is no study addressing whether or not EP is the mediator between ES and FP. Without recognizing such mediating effects, there is a lack of insight into how EP contributes to the enhancement of FP when ES is pursued. Second, most papers examining ES focus on proactive ES although ES is varied in degree. As a result, focus on type of ES may limit the understanding on that to what extent ES influences FP and EP. Following Kraus et al. (2020), this study considers that ES is a second-ordered construct. In

* Corresponding author

E-mail address: huynq121@,fe.edu.vn (Q.-H. Ngo)

(C) 2022 Growing Science Ltd. All rights reserved.

doi: $10.5267 /$ j.uscm.2021.10.013
Although prior studies draw upon natural resource-based views, environmental strategy permits mixed. To shed light on this issue, this study proposes that environmental performance mediates
mine the link between environmental strategy and financial performance. Data were collected from 175 square structural equation modeling was borrowed to test the data. The results reveal environmental performance partially mediates the link between environmental strategy and financial performance. By considering the mediating effect, this study contributes to the literature
by addressing the intervening mechanism of environmental performance on the inconclusive relationship between environmental strategy and financial performance. Besides, this study also of organizations pursuing this strategy, to explain how and why pursuing this strategy permits environmental and financial performance.
(C) 2022 Growing Science Ltd. All rights reserved. 
this regard, by using such operationalization, this study can gain insight into to what extent ES permits EP and FP. Third, although the examination of the positive effects of ES has gained much attention from scholars coming from different contexts, a lack of focus has been paid on the context of third-parties logistic service providers (TPLSPs). Thus. A more insight into this context is demanding because as argued by Yang (2018), in logistic context, enterprises are currently facing dual challenging issues relating to EP and FP. Specifically, due to the institutional pressure, these enterprises are required to enhance EP while maintaining competitive advantages to gain FP.

Addressing such gaps, this study draws upon the NBRV to propose the research framework indicating the mediating effects of EP on the relationship between ES and FP. This study uses data collected from 175 TPLSPs currently operating in Vietnam to examine the proposed research model. The results reveal that EP mediates the link between ES and FP. In this regard, this study contributes to the literature in several ways. First, a meta-analytical review reveals that the link between ES and FP is inclusive. One reason is that prior studies may examine only the direct relationship rather than indirect. As a result, it limits the understanding of the mediating effects on this relationship. This study shows that EP is the mediator of the link between ES and FP. In this regard, this study contributes to the environmental management literature by addressing the mediating role of EP when examining the indirect effects of ES on FP. In addition, this study also contributes to the growing body of environmental management research, which draws from NRBV to propose the research framework (see Clemens \& Bakstran, 2010) examining the mediating effect of EP (Aslam et al., 2021; Feng et al., 2018). Second, although the positive effect of ES has been examined in the context of TPLSPs recently, there is still a lack of understanding, which demands more insight. First of all, Laguir, Stekelorum, and El Baz (2020) found that TPLSPs pursuing proactive ES adopt green supply management practices, which leads to improvement of ES, and this ES induces economic performance. However, as argued by these authors, future studies should focus on other forms of ES to examine the relevance of the results. By considering ES is a multidimensional construct, which captures the degree from reactive to proactive, this study can provide a more comprehensive picture on whether or not TPLSPs pursuing ES can gain EP and FP. Second, a comprehensive review of Evangelista, Santoro, and Thomas (2018) reveals that a lack of attention has been paid to emerging countries located in the South East Asian region. Acknowledging this limitation, this study contributes to the environmental management literature of TPLSPs by focusing on the context of Vietnam. This paper was outlined as follows. After this section, theoretical concepts were revealed and the formation of the hypotheses was present. The following section introduces the methodology used in this study. And then, the result section was provided as well as the discussion section as follows. The last section concludes, showing the limitations and directions for future studies.

\section{Theoretical concept and hypothesis developments}

\subsection{Theoretical concept}

\section{Environmental strategy}

ES is a well-established plan to serve for the environmental protection purposes by reducing the impact of their operations on the natural environment (Bansal \& Roth, 2000). ES may vary in degree, which ranges from reactive, focused, opportunistic, and proactive (Lee \& Rhee, 2007). First, reactive ES refers to the passive actions toward environmental protection, and as a result, organizations pursuing this strategy are less likely to be concerned about how their operation has a negative impact on the environment. This strategy has the lowest score than other strategies in terms of environment protection (Kim, 2018). Second, organizations pursuing the second type of ES are more likely to have a higher degree of environmental concern than the first one because the aim of this strategy is to minimize risk, liabilities, and costs by integrating a limited numbers of environmental criteria into the strategic formulation (Lee \& Rhee, 2007; Roome, 1992). As a result, the purpose of pursuing this strategy is to comply with environmental regulations (Do, Nguyen, Nguyen, \& Johnson, 2019). The third type of ES has a higher degree of environmental concern in comparison to other two types (Lee \& Rhee, 2007). Pursuing this strategy encourages organizations to take into account more environmental criteria than the second type. However, in comparison to the last type, these organizations are less likely to commit to those criteria (Do et al., 2019). The fourth type of ES permits organizations to have a highest degree of environmental commitment. In this regard, these organizations are no longer driven by external pressure as environmental regulations. Instead, they are more likely to focus on environmental issues by taking actions to gain pollution control, green entrepreneurship, and reputation building (Eisenhardt \& Martin, 2000), which as such results in competitive advantages (Delmas, Hoffmann, \& Kuss, 2011).

\section{Natural resource-based view}

The resource-based view provides an insight into how organizations should sustain their competitive advantages. According to this view, organizational resources and capabilities, which are valuable, rare, imitable, and non-substitute, permits organizations to gain the sustainability of competitive advantages (Barney, 1991). However, this view does not take into account the role of the natural environment, and how this environment has an impact on operational activities, and how the alignment between natural environment and those activities permits sustainability of competitive advantages. As a result, an extension of this view called natural-resource based view was introduced later. According to this view, organizations can only successfully sustain their competitive advantages whenever they build their capabilities and resources facilitating 
environmentally sustainable economic activity (Hart, 1995). In this regard, this view concerns how organizations successfully develop their capabilities and resources to find competitive advantage while maintaining their operations to be friendly to the natural environment.

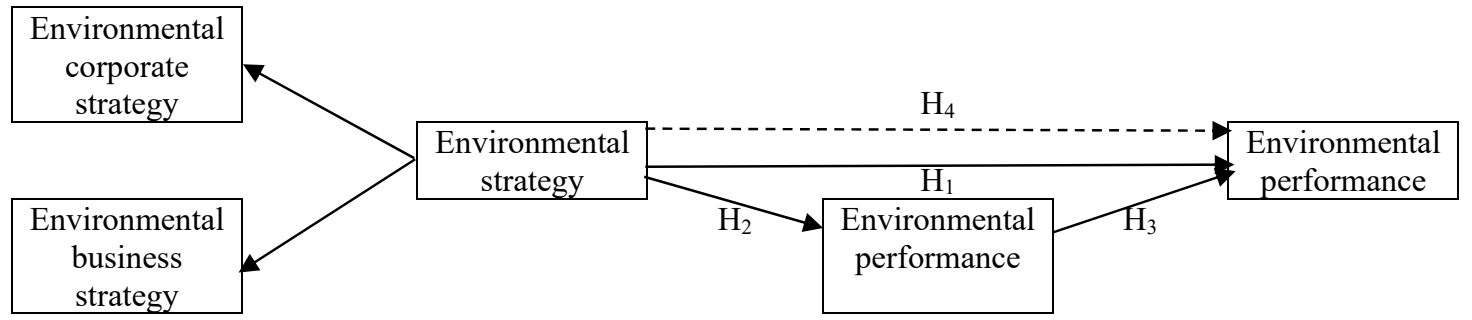

Fig. 1. Proposed research model

\subsection{Hypothesis developments}

\section{The link between ES and FP}

It is argued that strategic pursuit has a positive impact on performance (see Ngo, 2021a, 2021c). In environmental literature, although there are inclusive results relating to the association between ES and FP, most studies reveal the positive relationship (Aragón-Correa et al., 2008; Fousteris, Didaskalou, Tsogas, \& Georgakellos, 2018). According to the literature, there are several explanations for this positive relationship. pursuing ES permits differentiation and cost-leadership advantages (Dragomir, 2020) by adoption of green technology (Olson, 2008). First, it is argued that pollution is a sign of economic efficiency caused by incompleteness, inefficiency, or ineffectiveness of the operational processes (M. Porter \& C. Van der Linde, 1995). The adoption of green technology permits organizations to improve productivity and efficiency in terms of waste reduction, and as such, reduce the cost of these processes (see Albertini, 2013). Secondly, the adoption can also foster the green product and process innovation, which leads to differentiation advantages. Because the innovation of green technology allows the modification of existing or adding new processes to reduce environmental impacts, and in turn, results in the creation of new business through the development of environmentally-friendly products/services (Xie, Huo, \& Zou, 2019). In summary, this paper expects that ES allows the cost-leadership and differentiation advantage. And as argued by Porter (1980), these two advantages are crucial determination for performance. Thus, the first hypothesis is as follows.

\section{$\mathbf{H}_{1}$ : There is a positive association between ES and FP}

\section{The link between ES and EP}

According to (Kong, Yang, Liu, \& Yang, 2020), the actions of environmental protections can be determined by the strategic pursuit. ES is the strategy driving organizations to highlight the protection of the natural environment. As a result, Zhou, Shu, Jiang, and Gao (2019) raised a call for future studies, which addresses the driving role of ES on organizational actions relating to environmental protection. One way to measure the performance of such actions is to determine how ES has a positive impact on EP. This positive impact can be explained as follows. EP can be gained by reaching the environmental goals and objectives (see Eagan \& Joeres, 1997). These goals and objects allow the measurement of the impact of organizational operations on the natural environment. Pursuing ES encourages organizations to take actions to protect the environment, and in turn, these organizations are more likely to reduce the negative impact of their operations on the environment (see Jaeckel, 2020). Therefore, it is proposed that TPLSPs pursuing ES gain EP. This proposition is consistent with prior studies, which indicates the positive relationship between ES and EP (see Kraus et al., 2020; Latan et al., 2018; Solovida \& Latan, 2017). The second hypothesis was formulated as follows.

\section{$\mathbf{H}_{2}$ : There is a positive association between ES and EP.}

\section{The association between EP and FP}

Researchers have sought their efforts to examine the association between EP and FP. However, recent studies reveal the inclusive relationship between these two performances (see Horváthová, 2010). There are two contradicting arguments when examining this relationship. On the one hand, from the neoclassical economy, when organizations invest more to protect the environment, the cost relating to this investment occurs. This cost causes a burden on organizations, and as such, reduce FP. On the other hand, it is claimed that pollution is a sign of economic efficiency, and organizations can reduce this pollution through innovation, which neutralizes the additional cost incurred (Porter \& C. Van der Linde, 1995; Porter \& Van der Linde, 1995). In such regard, EP can be considered as a determination of FP. This study is in line with the later argument. More specifically, it is commonly argued that core competences are the source of competitive advantages. However, if the core competencies rely on technology, these competitive advantages are no longer sustained due to the change of the environment (Tushman \& Anderson, 1986). In this regard, NRBV can provide a proper explanation for the association between EP and 
FP. According to NRBV, pollution prevention, product stewardship, and sustainable development are the core drivers of FP, and this FP is the determination of the sustainability of competitive advantages (Hart, 1995). In this regard, if an organization continuously searches for new ways to deal with the natural environment, they are more likely to gather new capabilities, resources, and technology, which sustain their competitive advantages (Hang, Geyer-Klingeberg, \& Rathgeber, 2019). With such an argument, this study expects the positive association between EP and FP.

\section{$\mathbf{H}_{3}:$ There is a positive association between EP and EP.}

\section{The mediating effects of EP}

A meta-analytical review (see Albertini, 2013) suggests that the link between ES and FP is not always founded based on prior empirical studies results. Therefore, instead of examining the direct effects of ES on FP, indirect effects should be taken into account in order to gain insight into what the mechanism affect this relationship. Recently, scholars raise a concern that the link between ES and FP is influenced by mediators (Li et al., 2016). Consistently, some studies reveal that EP is the mediator on the link between environmental management practices and FP (Aslam et al., 2021; Feng et al., 2018). (Clemens \& Bakstran, 2010) proposed a framework, which reveals that EP is an organizational capability permitting the organization pursuing ES to gain FP. In summary, it can be expected the mediating effects of EP on the association between ES and FP. Thus, the last hypothesis is as follows.

\section{$\mathbf{H}_{4}$ : EP mediates the link between ES and FP.}

\section{Methods}

\subsection{Analytical procedure}

Due to the lack of direct measures relating to the variables in this study, a survey method was executed to collect data. After completing the data collection, this study examines common method bias because collecting the same survey may be subject to this bias. Next, partial least square structural equation modeling (PLS-SEM) was adopted. In the analysis, there are two stages: evaluation of measurement model and structural model. Lastly, a mediating assessment follows the approach of Zhao, Lynch Jr, and Chen (2010). This approach is commonly used in PLS-SEM studies (Ngo, 2020, 2021b).

\subsection{Data collection}

This study collects data by using the survey method. First of all, this study sends an email to 1,500 addresses of the managers who are currently working for TPLSPs located in Vietnam. The collecting process is about two months. After a month, a friendly reminder was sent to those addresses. At the end of the collection, the results reveal about 175 respondents agreeing to participate in the research. In this regard, the response rate is about $11.76 \%$.

\subsection{Measures}

There are three main latent variables used in this study. In this regard, to measure such variables, this study adopts and revises the instruments from prior studies. First, in line with Kraus et al. (2020), ES is a second-order construct, measured by the instruments of Banerjee (2002), which consists of two sub-constructs as environmental corporate strategy (ECS) and environmental business strategy (EBS). ECS has five items and EBS has three items. Second, similar to Laguir et al. (2020), EP is measured by using the instruments from Zhu and Sarkis (2004). In this instrument, there are six items. Third, an instrument consisting of four items was adopted from Wong and Merrilees (2015) to measure FP. All these items of the questionnaire are measured by using 5-point Likert's' scale ranging from "1" (totally disagree) to "5" (totally agree).

To control EP and FP, this study uses two variables. The first variable (YEAR) is measured by the number of years since the provider was established. The second variable (EMPLOYEE) is measured by the number of employees.

\subsection{Common method bias}

This study executes Harman's single factor test to assess whether or not common method bias causes a concern for data. The results indicate that $40.22 \%$ of total variances accounts for one factor. When there is a factor accounting more than $50 \%$ of total variances, there is a concern of common method bias (Podsakoff \& Organ, 1986). In this regard, this study can further analyze data without that concern. 


\section{Results}

\subsection{Measurement model}

Table 1

Indicators' loadings and reliability, convergent, and discriminant validity test

\begin{tabular}{|c|c|c|c|c|c|c|}
\hline First-order & Second-order & Indicators & Loadings & Cronbach's alpha & Composite & AVE \\
\hline \multirow{5}{*}{$\begin{array}{l}\text { Environmental } \\
\text { corporate strategy }\end{array}$} & & ECS 1 & 0.894 & \multirow{5}{*}{0.923} & \multirow{5}{*}{0.942} & \multirow{5}{*}{0.764} \\
\hline & & ECS_2 & 0.890 & & & \\
\hline & & ECS_3 & 0.870 & & & \\
\hline & & $\mathrm{ECS}_{-} 4$ & 0.866 & & & \\
\hline & & ECS 5 & 0.850 & & & \\
\hline \multirow{3}{*}{$\begin{array}{c}\text { Environmental } \\
\text { business strategy }\end{array}$} & & EBS_1 & 0.901 & \multirow{3}{*}{0.879} & \multirow{3}{*}{0.925} & \multirow{3}{*}{0.804} \\
\hline & & EBS_2 & 0.905 & & & \\
\hline & & EBS_3 & 0.883 & & & \\
\hline \multirow{8}{*}{$\begin{array}{l}\text { Environmental } \\
\text { performance }\end{array}$} & \multirow{8}{*}{$\begin{array}{c}\text { Environmental } \\
\text { strategy }\end{array}$} & ECS & 0.876 & \multirow{2}{*}{0.671} & \multirow{2}{*}{0.859} & \multirow{2}{*}{0.752} \\
\hline & & EBS & 0.859 & & & \\
\hline & & EP_1 & 0.851 & \multirow{6}{*}{0.906} & \multirow{6}{*}{0.927} & \multirow{6}{*}{0.681} \\
\hline & & EP_2 & 0.849 & & & \\
\hline & & EP_3 & 0.782 & & & \\
\hline & & $\mathrm{EP}_{-} 4$ & 0.880 & & & \\
\hline & & EP_5 & 0.798 & & & \\
\hline & & EP_6 & 0.787 & & & \\
\hline \multirow{4}{*}{$\begin{array}{c}\text { Financial } \\
\text { performance }\end{array}$} & & FP_1 & 0.818 & \multirow{4}{*}{0.849} & \multirow{4}{*}{0.898} & \multirow{4}{*}{0.688} \\
\hline & & FP_2 & 0.836 & & & \\
\hline & & FP_3 & 0.817 & & & \\
\hline & & $\mathrm{FP} 4$ & 0.848 & & & \\
\hline Size & & SIZE & 1.000 & 1.000 & 1.000 & 1.000 \\
\hline Year & & YEAR & 1.000 & 1.000 & 1.000 & 1.000 \\
\hline
\end{tabular}

Table 1 and Table 2 indicate that all measures are subject indicator reliability, internal consistency, convergent, and discriminant validity. First, the indicator loadings are sufficient because all loadings are above the value of 0.708 (Hair, Risher, Sarstedt, \& Ringle, 2019). Second, Cronbach's Alpha values are higher than the value of 0.6 (Sharma, 1996) and critical ratios are higher than the value of 0.7 (Hair et al., 2019). It means that the internal consistency between items of the corresponding construct is established. Third, average variance extracted (AVE) is higher than the value of 0.5 suggesting the establishment of convergent validity (Hair et al., 2019). Fourth, when the Heterotrait-Monotrait (HTMT) ratio of correlations is lower than the value of 0.85 , the discriminant validity is established (Henseler, Ringle, \& Sarstedt, 2015).

Table 2

Heterotrait-Monotrait ratio

\begin{tabular}{|c|c|c|c|c|c|c|c|}
\hline & EBS & ECS & ES & EP & FP & SIZE & YEAR \\
\hline \multicolumn{8}{|l|}{ EBS } \\
\hline ECS & 0.558 & & & & & & \\
\hline ES & - & - & & & & & \\
\hline EP & 0.454 & 0.404 & 0.574 & & & & \\
\hline FP & 0.341 & 0.333 & 0.452 & 0.521 & & & \\
\hline SIZE & 0.024 & 0.074 & 0.049 & 0.096 & 0.021 & & \\
\hline YEAR & 0.137 & 0.121 & 0.172 & 0.096 & 0.053 & 0.082 & \\
\hline
\end{tabular}

Note: - indicates the unexamined HTMT ratio

\subsection{Structural model}

To examine the fit of the structural model in SEM-PLS, this study assesses the collinearity, explanatory power and predictive accuracy by evaluating VIF, $R^{2}$, and Stone-Geisser $Q^{2}$ respectively. To do that, this study executed the bootstrapping procedure with 5.000 replacements. The results are shown in Table 3. According to (Hair et al., 2019), the cutoff values of these above criteria are as follows. First, VIF value needs to be higher than 3 . Second, $R^{2}$ in between 0.13 and 0.26 indicates the medium effect of explanatory power (Cohen, 2013). Third, $Q^{2}$ higher than zero shows the adequate degree of predictive accuracy. Since the fit of the PLS-SEM model is established based on the results from Table 3, it is safe to interpret the results of the hypotheses. Fig. 2 shows that all hypotheses are supported by data. First, the association between ES and FP is positively significant $(\beta=0.169, p=0.026)$. Second, the association between ES and FP is also significantly related ( $\beta=0.453$, $p<0.001)$. Third, EP has a significant relationship with FP $(\beta=0.385, p<0.001)$. Lastly, according to Zhao et al. (2010), the mediating effects of EP on the link between ES and FP is partial because of the following reasons. First, the first three hypotheses indicate the established relationship between the independent variable, mediator and dependent variable. Second, the mediating effect is significant $(\beta=0.175, p<0.001)$. Third, the confident interval is in between 0.093 and 0.269 . 
Table 3

$R^{2}, Q^{2}$, and VIFs

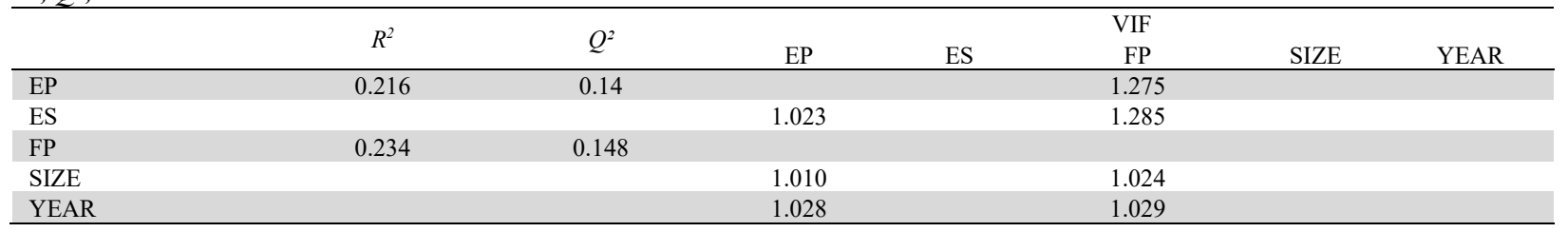

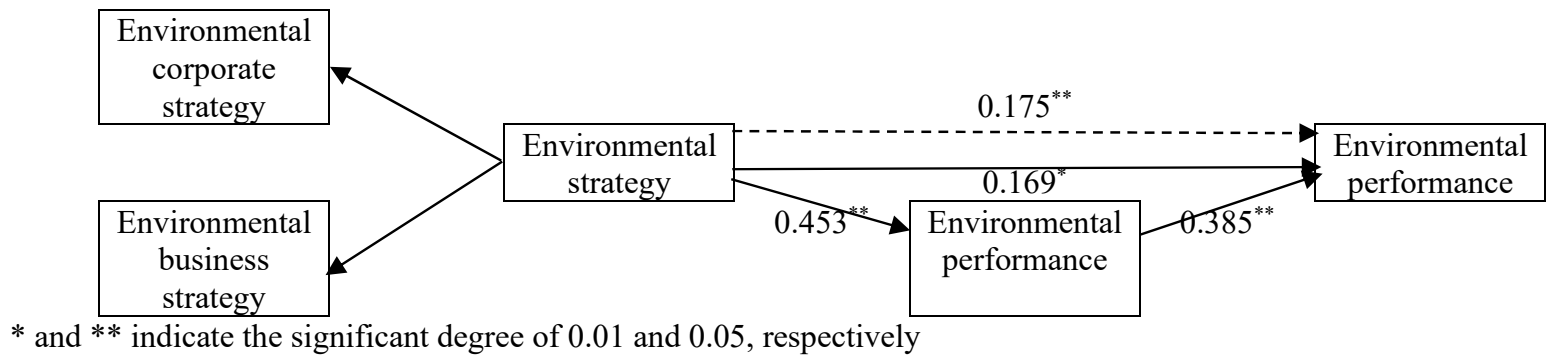

Fig. 2. Results of research model

\section{Discussions}

First, the finding indicates the positive association between ES and EP. From this finding, it is clear that TPLSPs pursuing ES can gain the implication of EP. Pursuing this strategy permits the setting of environmental goals and objectives to be taken into account during the formation of the strategy. Such setting drives TPLSPs to reduce the negative impact of their operations on environments (see Jaeckel, 2020), and as such translates into the implication of EP (see Eagan \& Joeres, 1997). It is consistent with previous studies in terms of the positive association between ES and EP (see Kraus et al., 2020; Latan et al., 2018; Solovida \& Latan, 2017). Second, the finding reveals the positive link between EP and FP. It indicates that TPLSPs, which obtain EP, gain FP. This finding is consistent with NRBV, which indicates that organizations successfully dealing with environmental concern, can gain competitive advantages. For example, when TPLSPs gain EP, they are more likely to reduce the waste during their operational processes. In this regard, they are less likely to execute additional environmental action as end-of-pipe technology to clean such waste. Thus, in terms of cost reduction, they don't need to add extra cost into their processes, which results in cost-leadership advantages. Second, gaining EP also permits TPLSPs to improve pollution prevention and service stewardship, which results in differentiation advantages (Maas, Schuster, \& Hartmann, 2014). Since these competitive advantages are argued to improve performance, high EP allows TPLSPs to gain FP. This finding is also consistent with prior studies, which reveals the positive relationship between these two types of performance (see Kraus et al., 2020; Latan et al., 2018; Solovida \& Latan, 2017). Third, the finding demonstrates the partial mediating effect of EP on the relationship between ES and FP. This finding suggests that the positive impact of ES on FP can be driven by the direct effect or indirect effect. Relating to the direct effect, this finding provides additional evidence, which is consistent with prior studies indicating the positive link between these two variables (Aragón-Correa et al., 2008; Fousteris et al., 2018). This finding refers to TPLSPs that can directly find FP when pursuing ES. Relating to the indirect effect, it is revealed the mediating effect of EP on the link between ES and FP. In this regard, TPLSPs cannot only enhance FP when pursuing ES but also improve FP through EP. The positive effects of ES on FP can be leveraged when TPLSPs gain EP.

\section{Conclusions, practical implications, and limitations}

This study's aim is to examine the mediating effect of EP on the link between ES and FP. Data were collected by using a survey method. There are 175 TPLSPs in the sample. PLS-SEM was used to analyze data. The results indicate that EP partially mediates the link between ES and FP. However, this study's findings are subject to some limitations. First, this study only collects data in Vietnam. The generalization of the findings to other countries is still questioned. Therefore, future studies should replicate this study to ensure the generalization of the findings. Second, this study uses subjective measure to measure FP, and thus, indicates a limitation. Thus, future studies should objectively measure. Third, the positive effect of ES and EP on FP may not be established immediately because they are long-term endeavors. This study uses cross-sectional data, and thus, limits this study to draw the conclusion that ES and EP has FP. Therefore, longitudinal data should be used to provide an insight into the change of those relationships.

\section{References}

Albertini, E. (2013). Does environmental management improve financial performance? A meta-analytical review. Organization \& Environment, 26(4), 431-457. 
Aragón-Correa, J. A., Hurtado-Torres, N., Sharma, S., \& García-Morales, V. J. (2008). Environmental strategy and performance in small firms: A resource-based perspective. Journal of Environmental Management, 86(1), 88-103.

Aslam, S., Elmagrhi, M. H., Rehman, R. U., \& Ntim, C. G. (2021). Environmental management practices and financial performance using data envelopment analysis in Japan: The mediating role of environmental performance. Business Strategy and the Environment, 30(4), 1655-1673.

Banerjee, S. B. (2002). Corporate environmentalism: The construct and its measurement. Journal of Business Research, 55(3), 177-191.

Bansal, P., \& Roth, K. (2000). Why companies go green: A model of ecological responsiveness. Academy of Management journal, 43(4), 717-736.

Barney, J. (1991). Firm resources and sustained competitive advantage. Journal of Management, 17(1), 99-120.

Clemens, B., \& Bakstran, L. (2010). A framework of theoretical lenses and strategic purposes to describe relationships among firm environmental strategy, financial performance, and environmental performance. Management Research Review.

Cohen, J. (2013). Statistical power analysis for the behavioral sciences: Academic press.

Delmas, M., Hoffmann, V. H., \& Kuss, M. (2011). Under the tip of the iceberg: Absorptive capacity, environmental strategy, and competitive advantage. Business \& Society, 50(1), 116-154.

Do, B., Nguyen, U., Nguyen, N., \& Johnson, L. W. (2019). Exploring the proactivity levels and drivers of environmental strategies adopted by vietnamese seafood export processing firms: A qualitative approach. Sustainability, 11(14), 3964.

Dragomir, V. D. (2020). Theoretical aspects of environmental strategy. In Corporate environmental strategy (pp. 1-31): SpringerRetrieved.

Eagan, P. D., \& Joeres, E. (1997). Development of a facility-based environmental performance indicator related to sustainable development. Journal of Cleaner Production, 5(4), 269-278.

Eisenhardt, K. M., \& Martin, J. A. (2000). Dynamic capabilities: what are they? Strategic Management Journal, 21(10-11), 1105-1121.

Evangelista, P., Santoro, L., \& Thomas, A. (2018). Environmental sustainability in third-party logistics service providers: A systematic literature review from 2000-2016. Sustainability, 10(5), 1627.

Feng, M., Yu, W., Wang, X., Wong, C. Y., Xu, M., \& Xiao, Z. (2018). Green supply chain management and financial performance: The mediating roles of operational and environmental performance. Business Strategy and the Environment, 27(7), 811-824.

Fousteris, A. E., Didaskalou, E. A., Tsogas, M.-M. H., \& Georgakellos, D. A. (2018). The environmental strategy of businesses as an option under recession in Greece. Sustainability, 10(12), 4399.

Hair, J. F., Risher, J. J., Sarstedt, M., \& Ringle, C. M. (2019). When to use and how to report the results of PLS-SEM. European Business Review, 31(1), 2-24.

Hang, M., Geyer-Klingeberg, J., \& Rathgeber, A. W. (2019). It is merely a matter of time: A meta-analysis of the causality between environmental performance and financial performance. Business Strategy and the Environment, 28(2), $257-273$.

Hart, S. L. (1995). A natural-resource-based view of the firm. Academy of Management Review, 20(4), 986-1014.

Henseler, J., Ringle, C. M., \& Sarstedt, M. (2015). A new criterion for assessing discriminant validity in variance-based structural equation modeling. Journal of the Academy of Marketing Science, 43(1), 115-135.

Horváthová, E. (2010). Does environmental performance affect financial performance? A meta-analysis. Ecological Economics, 70(1), 52-59.

Jaeckel, A. (2020). Strategic environmental planning for deep seabed mining in the area. Marine Policy, 114, 103423.

Kim, K. (2018). Proactive versus reactive corporate environmental practices and environmental performance. Sustainability, $10(1), 97$.

Kong, D., Yang, X., Liu, C., \& Yang, W. (2020). Business strategy and firm efforts on environmental protection: Evidence from China. Business Strategy and the Environment, 29(2), 445-464.

Kraus, S., Rehman, S. U., \& García, F. J. S. (2020). Corporate social responsibility and environmental performance: The mediating role of environmental strategy and green innovation. Technological Forecasting and Social Change, 160, 120262.

Laguir, I., Stekelorum, R., \& El Baz, J. (2020). Going green? Investigating the relationships between proactive environmental strategy, GSCM practices and performances of third-party logistics providers (TPLs). Production Planning \& Control, $1-14$.

Latan, H., Jabbour, C. J. C., de Sousa Jabbour, A. B. L., Wamba, S. F., \& Shahbaz, M. (2018). Effects of environmental strategy, environmental uncertainty and top management's commitment on corporate environmental performance: The role of environmental management accounting. Journal of Cleaner Production, 180, 297-306.

Lee, S. Y., \& Rhee, S. K. (2007). The change in corporate environmental strategies: a longitudinal empirical study. Management Decision, 45(2).

Li, S., Jayaraman, V., Paulraj, A., \& Shang, K.-c. (2016). Proactive environmental strategies and performance: Role of green supply chain processes and green product design in the Chinese high-tech industry. International Journal of Production Research, 54(7), 2136-2151.

Maas, S., Schuster, T., \& Hartmann, E. (2014). Pollution prevention and service stewardship strategies in the third-party logistics industry: Effects on firm differentiation and the moderating role of environmental communication. Business Strategy and the Environment, 23(1), 38-55. 
Ngo, Q.-H. (2020). Effectiveness of Management Accounting System in Public Healthcare Sector: An Empirical Investigation in Vietnam. Asian Journal of Business and Accounting, 13(2), 147-180.

Ngo, Q.-H. (2021a). How market orientation induces small businesses' performance: The role of strategic fits. Gadjah Mada International Journal of Business, 23(1), 55-75.

Ngo, Q.-H. (2021b). The impact of market orientation on small businesses' performance in Vietnam: The mediating effects of the management accounting system. Entrepreneurial Business and Economics Review, 9(3), 59-72.

Ngo, Q.-H. (2021c). The impact of prospecting strategy on small business performance in Vietnam: the role of broad-scope management accounting system. Strategic Management-International Journal of Strategic Management and Decision Support Systems in Strategic Management, 26(2).

Olson, E. G. (2008). Creating an enterprise-level "green" strategy. Journal of Business Strategy, 29(2).

Podsakoff, P. M., \& Organ, D. W. (1986). Self-reports in organizational research: Problems and prospects. Journal of Management, 12(4), 531-544.

Porter, M. (1980). Competitive strategy: Techniques for analyzing industries and competitors. New York: Free Press.

Porter, M., \& Van der Linde, C. (1995). Green and competitive: ending the stalemate. Harvard Business Review, 73(5).

Porter, M. E., \& Van der Linde, C. (1995). Toward a new conception of the environment-competitiveness relationship. Journal of Economic Perspectives, 9(4), 97-118.

Roome, N. (1992). Developing environmental management strategies. Business Strategy and the Environment, 1(1), 11-24.

Sharma, S. (1996). Applied multivariate techniques. New York, NY, United States: Wiley.

Solovida, G. T., \& Latan, H. (2017). Linking environmental strategy to environmental performance. Sustainability Accounting, Management and Policy Journal, 8(5), 595-619

Tushman, M. L., \& Anderson, P. (1986). Technological discontinuities and organizational environments. Administrative Science Quarterly, 31(1), 439-465.

Wong, H. Y., \& Merrilees, B. (2015). An empirical study of the antecedents and consequences of brand engagement. Marketing Intelligence \& Planning, 33(4), 575-591.

Xie, X., Huo, J., \& Zou, H. (2019). Green process innovation, green product innovation, and corporate financial performance: A content analysis method. Journal of Business Research, 101, 697-706.

Yang, C.-S. (2018). An analysis of institutional pressures, green supply chain management, and green performance in the container shipping context. Transportation Research Part D: Transport and Environment, 61, 246-260.

Zhao, X., Lynch Jr, J. G., \& Chen, Q. (2010). Reconsidering Baron and Kenny: Myths and truths about mediation analysis. Journal of Consumer Research, 37(2), 197-206.

Zhou, Y., Shu, C., Jiang, W., \& Gao, S. (2019). Green management, firm innovations, and environmental turbulence. Business Strategy and the Environment, 28(4), 567-581.

Zhu, Q., \& Sarkis, J. (2004). Relationships between operational practices and performance among early adopters of green supply chain management practices in Chinese manufacturing enterprises. Journal of Operations Management, 22(3), 265-289.

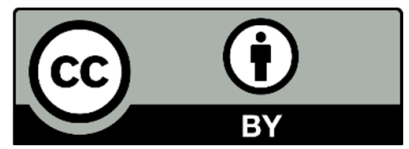

(C) 2022 by the authors; licensee Growing Science, Canada. This is an open access article distributed under the terms and conditions of the Creative Commons Attribution (CCBY) license (http://creativecommons.org/licenses/by/4.0/). 